\title{
Properties of Activated Carbon Regulated by Rapid Cooling Treatment after Pyrolysis
}

\author{
Bing Wang, ${ }^{\mathrm{a}}$ Huiyuan Chen, ${ }^{\mathrm{a}, *}$ Yonggang Li, ${ }^{\mathrm{b}, *}$ Hongyu Si, ${ }^{\mathrm{c}}$ Haomin Wei, ${ }^{\text {a Zupeng Guo, }}{ }^{\mathrm{a}}$ \\ Zhijie $\mathrm{Gu},{ }^{\mathrm{d}}$ and Dong $\mathrm{Hou}^{\mathrm{e}}$
}

\begin{abstract}
Effects of rapid cooling following pyrolysis were studied relative to the properties of activated carbon using different biomass as the raw materials. Coconut shell-based activated carbon (CSAC), bamboo-based activated carbon (BAC), and straw-based activated carbon (WSAC) were activated via high temperature and subsequently rapidly cooled to below minus $150^{\circ} \mathrm{C}$. The results showed that rapid cooling effectively increased the specific surface area, pore volume, and yield of activated carbons. Compared to natural cooling, rapid cooling increased the specific surface area of CSAC from $1076 \mathrm{~m}^{2} / \mathrm{g}$ to $1484 \mathrm{~m}^{2} / \mathrm{g}$, increased the pore volume from $1.46 \mathrm{~mL} / \mathrm{g}$ to $1.57 \mathrm{~mL} / \mathrm{g}$, decreased the average pore size from 2.25 $\mathrm{nm}$ to $2.13 \mathrm{~nm}$, and increased the yield from $27.1 \%$ to $31.5 \%$. The variation of the properties of activated carbon after rapid cooling using different raw materials and process conditions were studied using orthogonal experiments.
\end{abstract}

Keywords: Activated carbon; Rapid cooling; Specific surface area; Plant fibers

Contact information: a: College of Chemical Engineering, Qinghai University, Xining 810016, China; b: School of Chemical Engineering, Baise University, Baise 533000, China; c: Energy Institute of Shandong Academy of Sciences, Jinan, 250014, China; $d$ : Tokyo University of Agriculture and Technology, Tokyo, Japan; e: Department of Materials Science and Engineering, Norwegian University of Science and Technology, 7491 Trondheim, Norway;

*Corresponding authors: huiyuanchen97@163.com; 18209712799@126.com

\section{INTRODUCTION}

Activated carbon is processed from carbon-rich biomass including wood, forest, agricultural, and animal wastes (Maiti et al. 2014). Because of its high specific surface area and well-developed pore structure, activated carbon has been widely used in gas adsorption, supercapacitor electrodes, and other fields (Ambade et al. 2013). Phosphoric acid activation is a common method to prepare biomass-based activated carbons. It is mainly suitable for wood, bamboo, straw, and other agricultural and forestry biomass that contain plant fiber cell wall structures (Wang et al. 2018). Phosphoric acid can react with plant fiber in a series of condensation, cyclization, and cross-linking processes to produce a large number of hydrolysates and fill the vacancies of plant cell cavities and existing pipes, resulting in a redistribution of cell wall components (Huang et al. 2015).

The main chemical composition of plant fiber is derived from a complex polymer composed of a polysaccharide (general name of hemicellulose and cellulose) and lignin (Han et al. 2014). The hydrolysis of lignin is incomplete due to the lower temperature of phosphoric acid activation. The lignin residues still have the thermoplastic and glass transition properties of the polymer and become an important component of activated carbon (Zhuang and Feng 2016). 


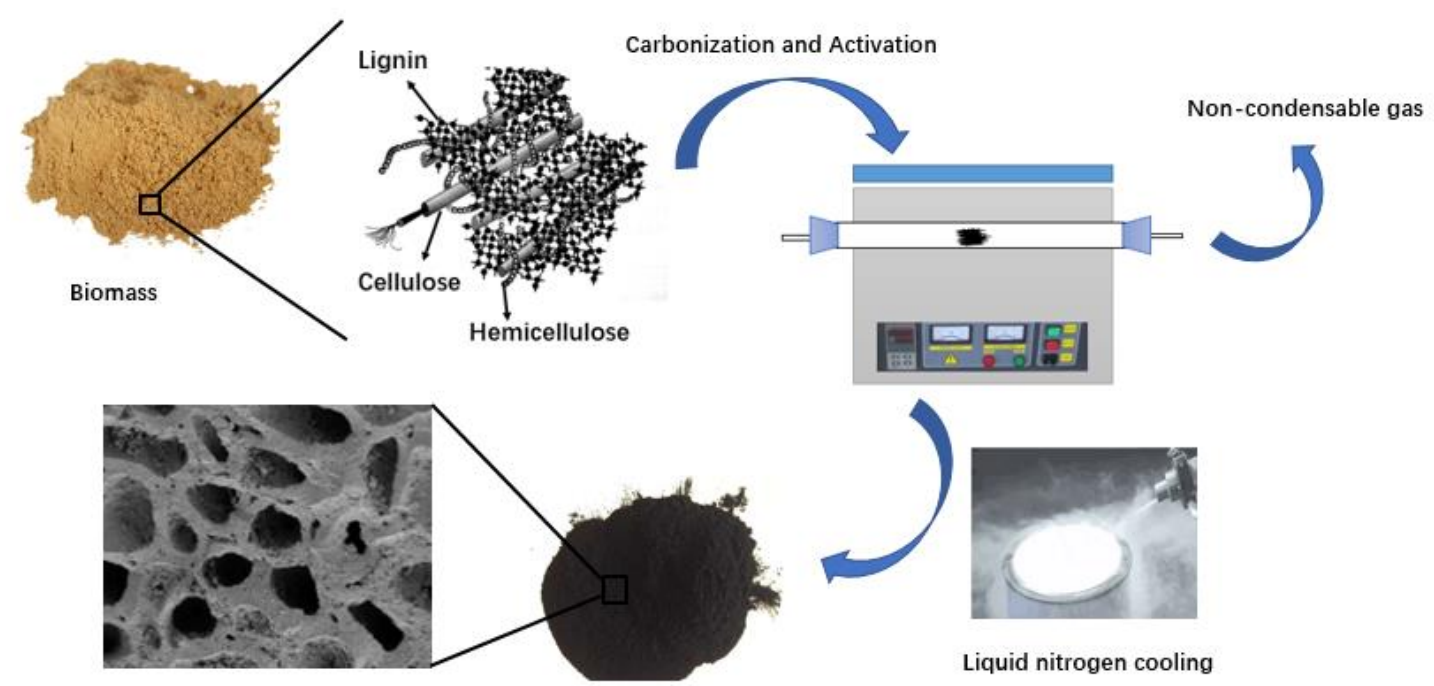

Fig. 1. Experimental setup for the rapid cooling treatment of activated carbons

When the high temperature activation is completed, the lignin residue can be rapidly changed from the high temperature viscous flow state to the glass state by speeding up the cooling rate, and the low molecular weight compounds produced by hydrolysis can be quickly fixed in the pores. Activated carbons, with abundant pores and high specific surface area, can be obtained after the removal of phosphoric acid and hydrolysate via washing (Choi et al. 2014). Therefore, rapid cooling treatment can be used as a new method to improve the specific surface area and adjust the pore volume and size of activated carbon. However, the properties of activated carbon are also affected by the biomass species, impregnation ratio, activation time, and temperature (Adinaveen et al. 2015), as well as the effect of the rapid cooling treatment under different process conditions can also influence the outcome.

The purpose of this study was to investigate the effects of the rapid cooling treatment on the properties of activated carbon and its applicability. Biomass from coconut shell, bamboo, and wheat straw were used as the raw materials. The effects of rapid cooling treatment on the properties of activated carbon obtained under different processes (biomass type, impregnation rate, activation temperature, and activation time) were investigated by orthogonal experiment. The specific surface area, pore volume, pore size, and yield of activated carbons prepared by rapid cooling (RC) and natural cooling (NC) were compared.

\section{EXPERIMENTAL}

\section{Materials}

\section{Preparation of activated carbon}

Coconut shell, bamboo, and wheat straw with a particle size between 2 and $3 \mathrm{~mm}$ were washed, cleaned, and dried at $110{ }^{\circ} \mathrm{C}$ for $12 \mathrm{~h}$. Each raw material was divided into two equal samples (10 g each), both of which were well-mixed with phosphoric acid solution for $2 \mathrm{~h}$. The impregnated raw materials were heated to $110{ }^{\circ} \mathrm{C}$ at a rate of $10{ }^{\circ} \mathrm{C}$ /min and maintained for $1 \mathrm{~h}$, and then heated to $400-500{ }^{\circ} \mathrm{C}$ in a nitrogen atmosphere. After activation, one mixture was rapidly immersed in liquid nitrogen and cooled to below $-150{ }^{\circ} \mathrm{C}$. The other mixture was naturally cooled to room temperature under $\mathrm{N}_{2}$ flow. 
Finally, after removing ash from the sample with $\mathrm{HCl}$ solution, and washing with boiling water to neutral, the activated carbon samples were obtained.

\section{Methods}

\section{Characterization of activated carbon}

The specific surface area and average pore size of the samples were measured using the Brunauer-Emmett-Teller (BET) method. The pore volume was measured using the Barrett-Joyner-Halenda (BJH) method using an automatic specific surface area and average pore size analyzer (3h-2000ps4; Bei Shi De Instrument, Beijing, China). Before the test, the activated carbon samples were degassed at $200{ }^{\circ} \mathrm{C}$ for $6 \mathrm{~h}$ to remove moisture and gas impurities.

\section{Orthogonal Experiments}

The effects of biomass species, impregnation ratio, activation temperature, and activation time on the properties of activated carbon prepared by RC and NC were studied using an orthogonal test system. As shown in Table 1, the orthogonal test table of L9 $\left(3^{4}\right)$ was designed with four different factors and three levels for each factor. There were nine groups of experiments in total.

Table 1. Factors and Levels of Orthogonal Experiments

\begin{tabular}{|c|c|c|c|c|}
\hline No. & $\begin{array}{c}\text { Biomass } \\
\text { Species } \\
(\mathrm{A})\end{array}$ & $\begin{array}{c}\text { Impregnation } \\
\text { Ratio } \\
(\mathrm{B})\end{array}$ & $\begin{array}{c}\text { Activation } \\
\text { Temperature } \\
\left({ }^{\circ} \mathrm{C}\right)(\mathrm{C})\end{array}$ & $\begin{array}{c}\text { Activation } \\
\text { Time } \\
(\mathrm{min})(\mathrm{D})\end{array}$ \\
\hline 1 & CSAC & $1: 1$ & 400 & 30 \\
\hline 2 & CSAC & $1.5: 1$ & 500 & 50 \\
\hline 3 & CSAC & $2: 1$ & 600 & 70 \\
\hline 4 & BAC & $1: 1$ & 500 & 70 \\
\hline 5 & BAC & $1.5: 1$ & 600 & 30 \\
\hline 6 & BAC & $2: 1$ & 400 & 50 \\
\hline 7 & WSAC & $1: 1$ & 600 & 50 \\
\hline 8 & WSAC & $1.5: 1$ & 400 & 70 \\
\hline 9 & WSAC & $2: 1$ & 500 & 30 \\
\hline
\end{tabular}

\section{RESULTS AND DISCUSSION}

Table 2 shows the specific surface area, pore volume, average pore size, and yield of activated carbon samples obtained via rapid cooling and natural cooling. Figure 2 depicts the trend of the effect of the rapid cooling treatment on the properties of activated carbon samples under different factors and levels.

As shown in Fig. 2, when compared with natural cooling, rapid cooling increased the specific surface area, pore volume, and yield of the activated carbon samples, and decreased the average pore size. Activated carbons were rapidly placed in liquid nitrogen after high temperature activation, and the residual lignin was changed from high temperature thermal deformation to vitrification (Li et al. 2014). Low molecular weight compounds produced by the hydrolysis of fibers were rapidly frozen and fixed in the pores. 
This cooling method avoids pore shrinkage and blockage, increases the number of pores, and results in a higher specific surface area and pore volume.

Table 2. Results of Orthogonal Test

\begin{tabular}{|c|c|c|c|r|c|c|c|c|}
\hline No. & \multicolumn{2}{|c|}{$\begin{array}{c}\text { Specific Surface Area } \\
\left(\mathrm{m}^{2} / \mathrm{g}\right)\end{array}$} & \multicolumn{2}{c|}{$\begin{array}{c}\text { Pore Volume } \\
(\mathrm{mL} / \mathrm{g})\end{array}$} & \multicolumn{2}{c|}{$\begin{array}{c}\text { Average pore size } \\
(\mathrm{nm})\end{array}$} & \multicolumn{2}{c|}{$\begin{array}{c}\text { Yield } \\
(\%)\end{array}$} \\
\cline { 2 - 10 } & $\mathrm{RC}$ & $\mathrm{NC}$ & $\mathrm{RC}$ & $\mathrm{NC}$ & $\mathrm{RC}$ & $\mathrm{NC}$ & $\mathrm{RC}$ & $\mathrm{NC}$ \\
\hline 1 & 1237 & 984 & 1.35 & 1.21 & 1.78 & 1.86 & 32.6 & 30.4 \\
\hline 2 & 1484 & 1076 & 1.57 & 1.46 & 2.13 & 2.25 & 31.5 & 27.1 \\
\hline 3 & 1343 & 1307 & 1.48 & 1.45 & 2.15 & 2.32 & 26.3 & 26.1 \\
\hline 4 & 1325 & 1207 & 1.25 & 1.19 & 3.03 & 3.12 & 23.1 & 22.7 \\
\hline 5 & 1266 & 1239 & 1.17 & 1.15 & 3.24 & 3.37 & 22.5 & 21 \\
\hline 6 & 1381 & 1187 & 1.19 & 1.08 & 3.41 & 3.6 & 24.5 & 22.4 \\
\hline 7 & 1021 & 986 & 1.12 & 1.14 & 3.95 & 3.96 & 21.5 & 21 \\
\hline 8 & 1076 & 1032 & 1.29 & 1.27 & 4.01 & 4.04 & 21.3 & 21.6 \\
\hline 9 & 1184 & 1201 & 1.33 & 1.32 & 4.31 & 4.33 & 22.6 & 22.1 \\
\hline
\end{tabular}

(A)

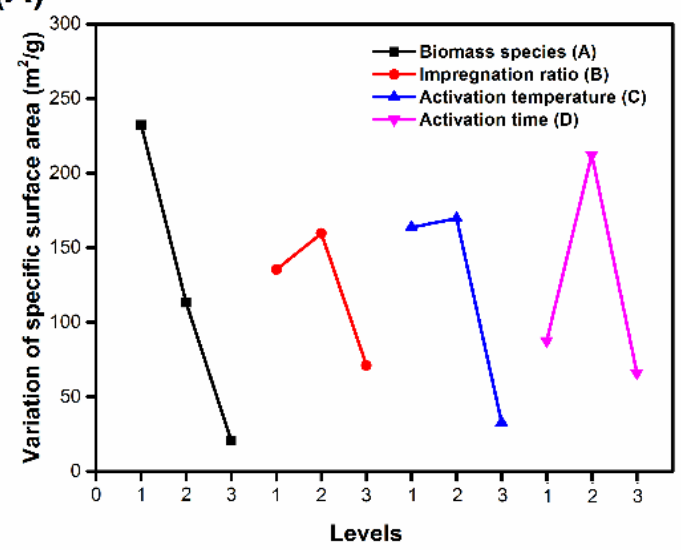

(C)

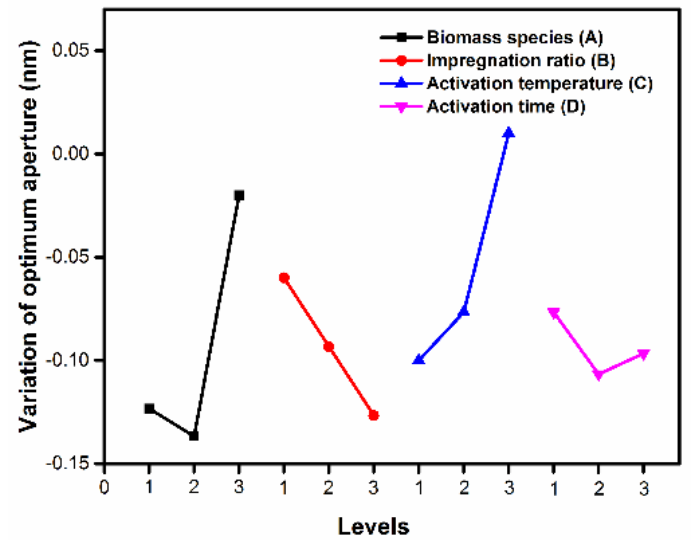

(B)

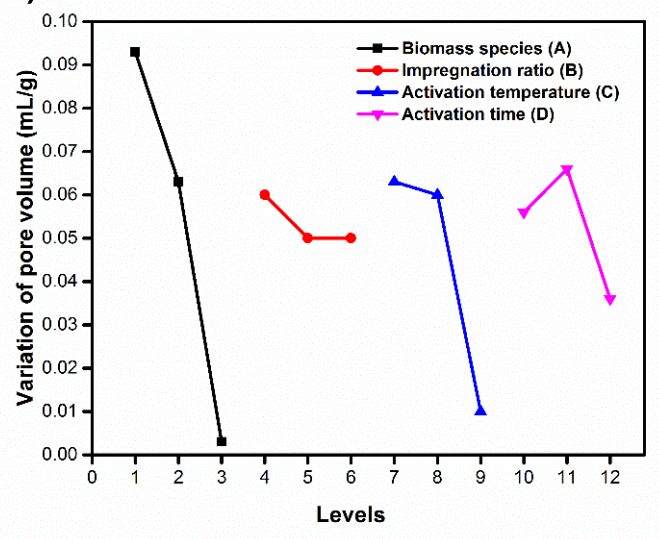

(D)

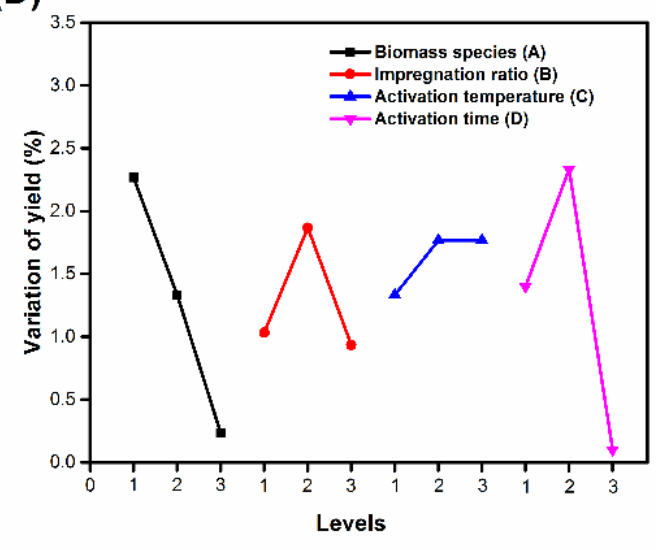

Fig. 2. The effects of rapid cooling treatment on the properties of activated carbon samples under different factors and levels

The properties of CSAC-RC and BAC-RC prepared with the rapid cooling treatment changed noticeably. In contrast, WSAC-RC showed no obvious change. The 
property differences for these three active carbons might result from the difference in the component content and degree of polymerization for the fiber raw materials. For example, coconut shell is the fruit of woody plants and bamboo is a highly lignified herb (Shrestha et al. 2017). The content of cellulose and lignin in the coconut shell is higher than that of bamboo, and the semi-fiber content is lower than that of bamboo (Sun et al. 2016). The degree of polymerization of hemicellulose is low, and the products are mostly noncondensable volatiles (Tian et al. 2017). Additionally, the degree of polymerization of cellulose is higher than that of hemicellulose for coconut shells and depolymerization at high temperature produces coke, gas, and condensable volatile products (Liang et al. 2017), which can help maintain the pore structure after a rapid cooling treatment. A higher lignin content resulted in a stronger ability to fix the pore structure when transitioning from a high temperature viscous state to a glassy state. Based on the above-mentioned facts, the number of pores in CSAC after rapid cooling was higher than that of BAC, and the specific surface area and pore volume increased more obvious.

As a low-lignified herb, wheat straw has higher hemicellulose and cellulose contents and a lower polymerization degree (Pekala et al. 1998). Phosphoric acid can penetrate into the raw material fiber relatively quickly, and while the condensable volatile matter generated during the process of hydrolyzing the fiber raw material is less, the noncondensable volatile matter is more (Hwang and Hyun 2004). In addition, wheat straw has a low hardness and low lignin content, making it difficult to provide a skeleton for the retention of pore structure. Therefore, the effect of the rapid cooling treatment on wheat straw-based activated carbon was not obvious.

The impregnation ratio had a noticeable effect on the pore size and pore volume of the activated carbon. At lower impregnation ratios, micropores in activated carbon develop quickly, while mesopores develop slowly (Fan et al. 2015). After rapid cooling, more microporous structures were retained in the activated carbon, the specific surface area and pore volume increased, and the average pore size had no noticeable changes. As the impregnation ratio increased, the microporous volume of the activated carbon no longer increased or even decreased, but the mesopores developed noticeably (Souza et al. 2004). After rapid cooling, more mesoporous structures were retained in the activated carbon, the average pore size was noticeably reduced, and the specific surface area had no significant changes.

When the activation temperature was low, rapid cooling markedly increased the specific surface area, pore volume, and yield of activated carbon. As the activation temperature increased, the hydrolysis rate of plant fibers increased. However, if the hydrolysis process is too fast, the produced low molecular compound cannot be condensed in time and undergoes secondary decomposing at high temperatures to form a noncondensable gas (Miao et al. 2013). The release of these non-condensable gases led to the collapse and shrinkage of the pores in activated carbons, resulting in a further decrease in specific surface area. Even if the temperature was immediately lowered to below $-150{ }^{\circ} \mathrm{C}$, it was still difficult to retain the pore structure formed by the activation. Therefore, when the activation temperature was higher than $500{ }^{\circ} \mathrm{C}$, the properties of the activated carbon prepared by rapid cooling showed no obvious change.

When the activation time is short, the hydrolysis of plant fibers is incomplete (Satoshi et al. 2005), and the properties of activated carbon show no noticeable variation after rapid cooling. As the activation time is prolonged, the hydrolysis of plant fibers produces more pore structures, while the small molecule gas produced by hydrolysis continuously escapes from the pores (Shown et al. 2015). Figure 2 shows that when the 
raw material was activated for 50 min and then rapidly cooled, the specific surface area and pore volume of the activated carbons were more obviously enhanced. When the hydrolysis of the plant fiber was completed, a longer residence time resulted in a worse rapid cooling effect.

\section{CONCLUSIONS}

1. Compared to natural cooling, rapid cooling increased the specific surface area of coconut shell-based activated carbon (CSAC) from $1076 \mathrm{~m}^{2} / \mathrm{g}$ to $1484 \mathrm{~m}^{2} / \mathrm{g}$, increased the pore volume from $1.46 \mathrm{~mL} / \mathrm{g}$ to $1.57 \mathrm{~mL} / \mathrm{g}$, decreased the average pore size from $2.25 \mathrm{~nm}$ to $2.13 \mathrm{~nm}$, and increased the yield from $27.1 \%$ to $31.5 \%$. Rapid cooling treatment had less effect on bamboo-based activated carbon (BAC) and wheat strawbased active carbon (WSAC) than CSAC, due to the difference of content and polymerization degree of the fiber raw materials in the biomass. The higher the content of cellulose and lignin in biomass and the degree of polymerization of fiber structure, the more obvious will be the effect.

2. The effect of the rapid cooling treatment on the properties of activated carbon was also related impregnation rate, activation temperature and activation time. When the impregnation ratio is $1: 1$, the activation temperature is $400^{\circ} \mathrm{C}$, and the activation time is $50 \mathrm{~min}$, the properties of the activated carbon can be markedly improved.

\section{ACKNOWLEDGMENTS}

This work was supported by the Special Fund for Agro-scientific Research in the Public Interest (201503135-04), the Natural Science Foundation of Shandong Province (ZR2016YL007), the "Chunhui Plan" of Ministry of Education PRC (Z2017039), and the project of basic research for application from Qinghai Science \& Technology Department (2017-ZJ-794).

\section{REFERENCES CITED}

Adinaveen, T., Kennedy, L. J., and Vijaya, J. J. (2015). "Surface and porous characterization of activated carbon prepared from pyrolysis of biomass (rice straw) by two-stage procedure and its applications in supercapacitor electrodes," Journal of Material Cycles and Waste Management 17(4), 736-747. DOI: 10.1007/s10163-0140302-6

Ambade, R. B., Ambade, S. B., Shrestha, N. K., Nah, Y. C., Han, S. H., and Lee, W. (2013). "Polythiophene infiltrated $\mathrm{TiO}_{2}$ nanotubes as high-properties supercapacitor electrodes," Chemical Communications 49(23), 2308-2310.

DOI: $10.1039 / \mathrm{c} 3 \mathrm{cc} 00065 \mathrm{f}$

Choi, C., Lee, J. A., Choi, A. Y., Kim, Y. T., Lepró, X., and Lima, M. D. (2014). "Flexible supercapacitor made of carbon nanotube yarn with internal pores," Advanced Materials 26(13), 2059-2065. DOI: 10.1002/adma.201304736 
Fan, X. Z., Xu, H., and Lu, Y. (2015). "Electrochemical modification and its effect on the pseudo capacitive properties of a graphite electrode," Carbon 85, 448. DOI: 10.1016/j.carbon.2014.12.086

Han, J., Xu, G., Ding, B., Pan, J., Dou, H., and Macfarlane, D. R. (2014). "Porous nitrogen-doped hollow carbon spheres derived from polyaniline for high properties supercapacitors," Journal of Materials Chemistry A 2(15), 5352-5357. DOI: 10.1039/C3TA15271E

Huang, K. J., Wang, L., Zhang, J. Z., and Xing, K. (2015). "Synthesis of molybdenum disulfide/carbon aerogel composites for supercapacitors electrode material application," Journal of Electroanalytical Chemistry 752, 33-40.

DOI: 10.1016/j.jelechem.2015.06.005

Hwang, S. W., and Hyun, S. H. (2004). "Capacitance control of carbon aerogel electrodes,” Journal of Non-Crystalline Solids 347(1-3), 238-245. DOI: 10.1016/j.jnoncrysol.2004.07.075

Li, P., Yang, Y., Shi, E., Shen, Q., Shang, Y., and Wu, S. (2014). "Core-double-shell, carbon nanotube@polypyrrole@ $\mathrm{MnO}_{2}$ sponge as freestanding, compressible supercapacitor electrode," ACS Applied Materials \& Interfaces 6(7), 5228-5234. DOI: $10.1021 / \mathrm{am} 500579 \mathrm{c}$

Liang, C., Bao, J., Li, C., Huang, H., Chen, C., and Lou, Y. (2017). “One-dimensional hierarchically porous carbon from biomass with high capacitance as supercapacitor materials," Microporous and Mesoporous Materials 251, 77-82. DOI: 10.1016/j.micromeso.2017.05.044

Maiti, U. N., Lim, J., Lee, K. E., Lee, W. J., and Kim, S. O. (2014). “Three-dimensional shape engineered, interfacial gelation of reduced graphene oxide for high rate, large capacity supercapacitors," Advanced Materials 26(4), 615-619. DOI: 10.1002/adma.201303503

Miao, Y. E., Fan, W., Chen, D., and Liu, T. (2013). "High-properties supercapacitors based on hollow polyaniline nanofibers by electrospinning," ACS Applied Materials \& Interfaces 5(10), 4423-4428. DOI: 10.1021/am4008352

Pekala, R. W., Farmer, J. C., Alviso, C. T., Tran, T. D., and Dunn, B. (1998). "Carbon aerogels for electrochemical applications," Journal of Non-Crystalline Solids 225(1), 74-80. DOI: 10.1016/S0022-3093(98)00011-8

Satoshi, M., Sang-Ick, L., Koji, S., Seong-Ho, Y., Yozo, K., and Isao, M. (2005). "Activation of coal tar derived needle coke with $\mathrm{K}_{2} \mathrm{CO}_{3}$ into an active carbon of low surface area and its properties as unique electrode of electric double-layer capacitor," Carbon 43(14), 2960-2967. DOI: 10.1016/j.carbon.2005.05.047

Shown, I., Ganguly, A., Chen, L. C., and Chen, K. H. (2015). "Conducting polymerbased flexible supercapacitor," Energy Science \& Engineering 3(1), 2-26. DOI: 10.1002/ese 3.50

Shrestha, M., Amatya, I., Wang, K., Zheng, B., and Fan, Q. H. (2017). "Electrophoretic deposition of activated carbon yp-50 with ethyl cellulose binders for supercapacitor electrodes," Journal of Energy Storage 13, 206-210. DOI: 10.1016/j.est.2017.07.015

Souza, A. R. D., Arashiro, E., Golveia, H., and Lassali, T. A. F. (2004). "Pseudocapacitive behavior of $\mathrm{Ti} / \mathrm{RhO}_{\mathrm{x}}+\mathrm{Co}_{3} \mathrm{O}_{4}$ electrodes in acidic medium: Application to supercapacitor development," Electrochimica Acta 49(12), 2015-2023. DOI: 10.1016/j.electacta.2003.12.031 
Sun, W., Lipka, S. M., Swartz, C., Williams, D., and Yang, F. (2016). "Hemp-derived activated carbons for supercapacitors," Carbon 103, 181-192. DOI: 10.1016/j.carbon.2016.02.090

Tian, X., Zhu, S., Peng, J., Zuo, Y., Wang, G., and Guo, X. (2017). "Synthesis of microand meso-porous carbon derived from cellulose as an electrode material for supercapacitors," Electrochimica Acta 241, 170-178. DOI: 10.1016/j.electacta.2017.04.038

Wang, B., Li, Y. G., and Si, H. Y. (2018). "Analysis of the physical and chemical properties of activated carbons based on hulless barley straw and plain wheat straw obtained by $\mathrm{H}_{3} \mathrm{PO}_{4}$ activation," BioResources 13(3), 5204-5212. DOI: 10.15376/biores.13.3.5204-5212

Zhuang, X., and Feng, X. (2016). "Silicon-compatible carbon-based microsupercapacitors," Angewandte Chemie International Edition 55(21), 6136-6138. DOI: 10.1002/anie. 201603040

Article submitted: May 7, 2019; Peer review completed: July 21, 2019; Revised version received: July 23, 2019; Accepted: August 1, 2019; Published: August 15, 2019.

DOI: $10.15376 /$ biores.14.4.7935-7942 